\title{
Method Development Technologies for Clopidogrel Bisulphate by Improving Solubility and Bioavailability
}

\author{
Deevan Paul A*, Avilala Neelima, Chitra Prasanthi, Navyaja Kota \\ Department of Pharmaceutics, SVU College of Pharmaceutical Sciences, SV University, Tirupati, Andhra Pradesh, India - 517502.
}

\begin{abstract}
Clopidogrel bisulphate (CB) is a crystalline, poorly water-soluble drug of bioavailability less than $50 \%$. The drug is an irreversible inhibitor of the P2Y12 adenosine diphosphate receptor found on the membranes of platelet cells. The present work was performed using different polymers such as Polyvinylpyrrolidone (PVP) K-30 and polyvinyl alcohol with varied surfactants such as Tween 80 in comparison by using superdisintegrants like Sodium Starch Glycolate (SSG) and Microcrystalline Cellulose (MCC). By performing the particle size distribution, the size ranges from $232.6 \mathrm{~nm}$ to $995.6 \mathrm{~nm}$ and the polydispersity index ranges from 0.11 to 0.96 , these ranges indicating the good physical nature of nanoparticles. The drug entrapment efficiency (DEE) of clopidogrel bisulphate nanoparticles was found to be in the range of $30.10 \%$ to $94.4 \%$. From the study, it was found that F2 formulation containing PVP K-30 and L-arginine has given the best release in 80 mins and the maximum cumulative drug release was $96.8 \%$ in comparison with other formulation, and the dissolution studies were performed for the seven formulations of prepared clopidogrel bisulphate granules among which F5 formulation containing crospovidone has given maximum drug release of $91.6 \%$ within $80 \mathrm{mins}$. Here we state that the method development technologies improve the solubility and bioavailability studies by producing the nanoparticles.
\end{abstract}

Keywords: Bioavailability; Clopidogrel bisulphate; Drug Entrapment Efficiency; Polydispersity Index; Superdisintegrants.

\section{INTRODUCTION}

The rate and degree of drug absorption, as well as its bioavailability, are regulated by solubility, dissolution, and gastrointestinal permeability. A drug's water solubility is a critical property that affects its absorption after oral administration. It also decides whether a drug can be administrated parenterally and is useful in manipulating and testing drug properties during the drug design and development process. The drug solubility is an equilibrium measure but also the dissolution rate at which the solid drug or drug from the dosage form passes into solution is critically important when the dissolution time is rate limited. ${ }^{1}$

The parameters including dissolution rate, first-pass metabolism are susceptibility to efflux mechanisms and these are important factors in oral bioavailability. ${ }^{2}$ Clopidogrel bisulphate, an antiplatelet agent which is structurally and pharmacologically similar to ticlopidine, is used to inhibit blood clots in a variety of conditions such as peripheral vascular disease, coronary artery disease, and cerebrovascular disease. The drug inhibits the P2Y12 adenosine diphosphate receptor on platelet cell membranes in an irreversible manner. Clopidogrel use is linked to several serious side effects, including extreme neutropenia, different types of hemorrhage and cardiovascular edema. A compound solubility is determined by its composition and solution conditions. Lipophilicity is determined by structure, hydrogen bonding, molecular volume, crystal energy which determine solubility. Solution conditions are affected by $\mathrm{pH}$, co-solvents, additives, ionic strength, time, and temperature. ${ }^{3}$ Poorly soluble compounds can dramatically reduce productivity in drug discovery and development.

\section{MATERIAL AND METHODS}

\subsection{Chemicals and reagents}

Clopidogrel bisulphate is obtained as a generous gift sample from Pharmazel Pvt, Ltd, Vizag. L-Arginine (SD Fine chem Limited, Gujarat), PVPK-30 and Tween 80 (SR Scientifics Labs, Tirupati), MCC, and Cross

\section{Corresponding author}

Dr. A. Deevan Paul

Email : deevan4@gmail.com 
povidone (CP) (SR Scientifics Labs, Tirupati), PEG 6000 (Himedia).

\subsection{Preparation of clopidogrel bisulphate nanoparticles}

Clopidogrel nanoparticles were prepared by the precipitation technique in separate entities, which is also called the anti-solvent precipitation method. Drugs were dissolved in methanol $(3 \mathrm{ml})$ at room temperature, this was poured into $10 \mathrm{ml}$ of water containing different types of surfactants (alone and in combination) maintained at a temperature of $50^{\circ} \mathrm{C}$ and subsequently stirred at an agitation speed of 250 revolutions per minute ( $\mathrm{rpm}$ ) on a magnetic stirrer for 1 hour to allow the volatile solvent to evaporate. Addition of organic solvents using a syringe drop by drop positioned with the needle directly into the surfactant-containing water. The ratio of drug to the surfactant used was 1:2. Formulation undergoes 10 formulas (F1-F10) which were demonstrated in Table 1 with their composition.

\subsection{Post formulation studies for nanoparticles (particle size analysis, polydispersity index (PDI), zeta potential and drug entrapment efficiency)}

Particle size determination of the prepared formulas (F1F15) was done by using the ABT-9000 Nano-laser particle size analyzer at scattering angle $90^{\circ}$. The average particle size analyzer which is also called volume moment mean reflects the size of those particles which constitute the bulk of the sample volume, was measured after experimenting with triplicates. The PDI of each formula was also determined as a measurement for the width of the size distribution, it is a parameter to define the particle size distribution of nanoparticles obtained from a particle analyzer. PDI is an index of width or spread or variation within the particle size distribution. The analyzer also determines the specific surface area for each sample. The freshly prepared liquid nanoparticles were centrifuged at 20,000 rpm for 20 minutes using an ultracentrifuge. The amount of unincorporated drug was measured by taking the absorbance of the appropriately diluted $25 \mathrm{ml}$ of the supernatant solution at $268 \mathrm{~nm}$ using a UV spec- trophotometer. DEE was calculated by subtracting the amount of free drug in the supernatant from the initial amount of drug taken. The experiment was performed in triplicate. ${ }^{4}$ Drug entrapment efficiency (DEE\%) could be achieved by the following equation:

Entrapment Efficiency $(\%)=\frac{W(\text { Initial Drug })-W(\text { Free Drug })}{W(\text { Initial Drug })} \times 10$

\subsection{Percentage cumulative drug release of clopidogrel bisulphate nanoparticles}

In-vitro dissolution study of nanoparticles was performed using USP dissolution test apparatus-II (paddle assembly). The dissolution was performed using dialysis membrane-60 in $900 \mathrm{ml}$ of phosphate buffer solution (PBS) of $\mathrm{pH} 6.8$ as dissolution mediums containing $1 \%$ Sodium lauryl sulphate (SLS) maintained at $37 \pm 0.5^{\circ} \mathrm{C}$ and $50 \mathrm{rpm}$ for clopidogrel nanoparticles formulations. The freshly prepared clopidogrel nanoparticles $(10 \mathrm{ml})$ were added to a dialysis bag and fitted to the paddle, samples $(5 \mathrm{ml})$ were withdrawn at regular intervals of 10 minutes for $80 \mathrm{mins}$ and replaced with a fresh dissolution medium to maintain sink condition. Samples were filtered through filter paper and assayed spectrophotometrically on UVVisible spectrophotometer at $268 \mathrm{~nm}$ wavelength. ${ }^{5}$ The release of the selected formulation was compared with the pure drug in both the media of $0.1 \mathrm{~N} \mathrm{HCl}$ and phosphate buffer $\mathrm{pH}$ 6.8. The release of the drug by using 0.1 $\mathrm{N} \mathrm{HCl}$ was performed for about $12 \mathrm{hrs} .^{6}$

\subsection{Preparation of clopidogrel bisulphate tablets using superdisintegrants}

Clopidogrel bisulfate tablets were prepared by direct compression method after freeze-drying of the ideal formulation that gave the best in vitro dissolution profile in 10 minutes in comparison with other nanoparticle formulations and pure drug. The amount of powder was taken and prepared using microcrystalline cellulose MCC, PVPK30, Polyethylene glycol PEG 6000, and SSG as a diluent, binder, lubricant, and disintegrants at different concentration and tested to obtain the optimum formulation that shows the accepted hardness and the best in-vitro dissolution profile. ${ }^{7}$ The composition of nanoparticle tablets is indicated in Table 2.

Table 1: Formulation of clopidogrel nanosuspensions using different stabilizers

\begin{tabular}{lllllllllll}
\hline Materials $(\mathrm{mg})$ & $F 1$ & $F 2$ & $F 3$ & $F 4$ & $F 5$ & $F 6$ & $F 7$ & $F 8$ & $F 9$ & $F 10$ \\
\hline Clopidogrel Bisulphate & 75 & 75 & 75 & 75 & 75 & 75 & 75 & 75 & 75 & 75 \\
L- arginine & 95 & 95 & 95 & 95 & - & - & - & - & - & - \\
PVPK-30 & - & 95 & - & - & 95 & - & - & 95 & 95 & - \\
Polyvinyl Alcohol & - & - & 95 & - & - & 95 & - & 95 & - & 95 \\
Tween 80 & - & - & - & 0.1 & - & - & 0.1 & - & 0.1 & 0.1 \\
Methanol & 3 & 3 & 3 & 3 & 3 & 3 & 3 & 3 & 3 & 3 \\
Water & 10 & 10 & 10 & 10 & 10 & 10 & 10 & 10 & 10 & 10 \\
\hline
\end{tabular}


Table 2: Composition of Clopidogrel Nanoparticle Tablets Using Different Superdisintegrants

\begin{tabular}{|c|c|c|c|c|c|c|c|}
\hline Materials (mg) & $F 1$ & $F 2$ & F3 & $F 4$ & F5 & F6 & $F 7$ \\
\hline Clopidogrel bisulphate & 75 & 75 & 75 & 75 & 75 & 75 & 75 \\
\hline MCC & 95 & 100 & 80 & 50 & - & - & - \\
\hline PVPK 30 & - & - & 20 & 50 & - & - & - \\
\hline Cross Povidone & - & - & - & - & 100 & - & 50 \\
\hline SSG & 5 & - & - & - & - & - & - \\
\hline Cross Carmellose & - & - & - & - & - & 100 & 50 \\
\hline PEG 6000 & 6 & 6 & 6 & 6 & 6 & 6 & 6 \\
\hline Flavour & 1 & 1 & 1 & 1 & 1 & 1 & 1 \\
\hline
\end{tabular}

\subsection{Precompression parameters}

The flowability of powder is of critical importance in the production of pharmaceutical dosage forms to get a uniform feed, as well as the reproducible filling of the tablet in dies otherwise high dose variations, will occur. The powder flowability of prepared clopidogrel tablets was characterized by an angle of repose and Carr's index.

\subsubsection{Angle of repose}

The angle of repose is defined as the maximum angle that varies between the surface of a pile and horizontal aircraft of powder. ${ }^{8}$ The frictional pressure in an unfastened powder or granules can be measured by using the angle of repose.

$$
\emptyset=\tan ^{-1} \frac{\mathrm{h}}{\mathrm{r}}
$$

where, $\varnothing$ is the angle of repose his height of pile, $r$ is the radius of the base of the pile.

Different ranges of flowability in terms of angle of repose are given in Table 3.

\subsubsection{Bulk density}

\subsubsection{Loose bulk density (LBD) $\left(\mathrm{g} / \mathrm{cm}^{3}\right)$}

Loose bulk density (LBD) was measured using the formula:

$$
\mathrm{LBD}=\frac{\text { weight of the powder }}{\text { volume of the packing }}
$$

\subsubsection{Tapped bulk density (TBD) $\left(\mathrm{g} / \mathrm{cm}^{3}\right)$}

Tapped bulk density (TBD) were measured using the formula

$$
\mathrm{TBD}=\frac{\text { weight of the powder }}{\text { tapped volume of the packing }}
$$

\subsubsection{True density}

The true density of granules is carried out by using a specific gravity bottle and calculated by using the formula,

$$
\text { True density }=\left(\mathrm{W}_{2}-\mathrm{W}_{4}\right)\left(\mathrm{W}_{1}-\mathrm{W}_{3}\right) / \mathrm{Q}
$$

where, $\quad W_{1}=$ Empty bottle weight
Table 3: The relationship between the angles of repose and flow properties

\begin{tabular}{ll}
\hline Angle of Repose & Flow \\
\hline$<25$ & Excellent \\
$25-30$ & Good \\
$30-40$ & passable \\
$>40$ & Very poor \\
\hline
\end{tabular}

$\mathrm{W}_{2}=$ weight of bottle with $3 / 4^{\text {th }}$ of liquid

$W_{3}=$ weight of bottle with $1 / 4^{\text {th }}$ quantity of powder

$\mathrm{W}_{4}=$ Final weight of the bottle with powder and liquid

\subsubsection{Carr's index}

It is a simple test to evaluate the bulk density and true density of a powder and the rate at which it was packed down. The formula for Carr's index is as below:

$$
\text { Carr's index }=\frac{\text { Tapped Density }- \text { Bulk Density }}{\text { Tapped Density }} \times 100
$$

\subsubsection{Haussner's ratio}

Haussner's Ratio is a number that is correlated to the flowability of a powder.

$$
\text { Haussner's Ratio }=\frac{\text { Tapped Density }}{\text { Bulk Density }}
$$

\subsection{Percentage cumulative drug release of clopidogrel bisulphate granules using super disintegrants}

In-vitro dissolution studies for granules were performed by using USP dissolution test apparatus-II (paddle assembly). The dissolution was performed using $900 \mathrm{ml}$ of 0.1 $\mathrm{N} \mathrm{HCl}$ and phosphate buffer solution of $\mathrm{pH} 6.8$ as dissolution mediums maintained at $37 \pm 0.5^{\circ} \mathrm{C}$ and $50 \mathrm{rpm}$ for ideal tablet formulation formula in comparison with marketed clopidogrel tablet. Samples $(5 \mathrm{ml})$ were withdrawn at regular intervals of 10 minutes for 80 minutes in $0.1 \mathrm{~N} \mathrm{HCl}$ and replaced with a fresh dissolution medium to keep sink condition. ${ }^{9}$ Samples were filtered through filter paper and assayed spectrophotometrically on UVVISIBLE spectrophotometer at $230 \mathrm{~nm}$ wavelength for 0.1 $\mathrm{N} \mathrm{HCl}$ and $260 \mathrm{~nm}$ for PBS $\mathrm{pH}$ 6.8. ${ }^{10}$ 


\section{RESULTS AND DISCUSSION}

\subsection{Fourier transform infra-red spectroscopy}

The FT-IR spectra of the pure drug clopidogrel bisulphate, polyvinyl pyrrolidone, polyvinyl alcohol, SSG, MCC and L-arginine. The drug-polymer mixture was recorded to check the interaction between drug and polymers. The characteristic peaks of clopidogrel bisulphate appeared in all the spectra and values were shifted due to the formation of the complex. The results showed that the characteristic peak of clopidogrel bisulphate was 3120 $\mathrm{cm}^{-1}$ which is due to the C-H stretching of the functional group present in the entire spectrum. This indicated that there was no chemical interaction between clopidogrel bisulphate and other excipients (Fig. 1-6).

\subsection{Evaluation studies for nanoparticles}

\subsubsection{Determination of particle size $(\mathrm{nm})$ and} PDI

Particle size analysis of the prepared clopidogrel bisulphate nanoparticles was measured by using ABT-9000 nanolaser particle size ranges from 232.6 to $995.6 \mathrm{~nm}$ among all the formulations, $\mathrm{F}_{2}$ showing the best result.

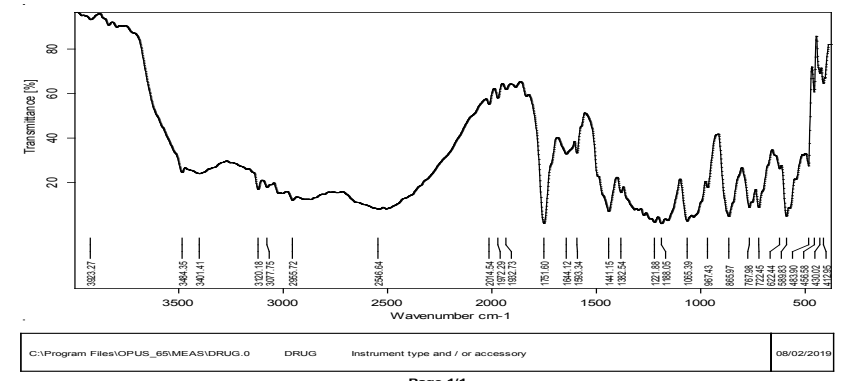

Fig. 1: FT-IR Spectrum of CB

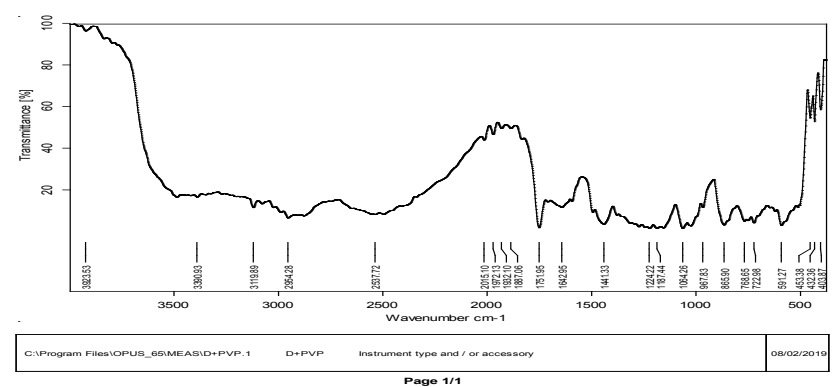

Fig. 2: FT-IR spectrum of $C B$ and PVP

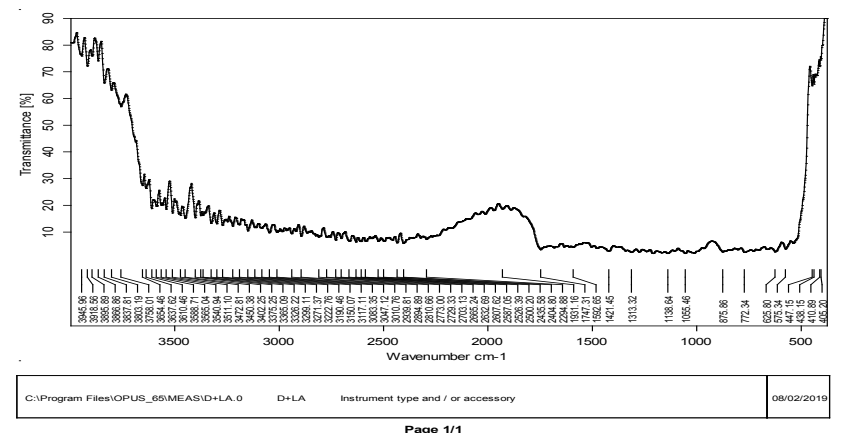

Fig. 3: FT-IR spectrum of drug and L-arginine
The effect of the release of the drug from the matrix at different time intervals on dissolution shows that pores are formed for the release of the drug. The effect of stirring rate on the particle size of the clopidogrel bisulphate nanoparticle is shown in Table 4. Here the particle size is increased and the number of particles is decreased.

\subsubsection{Determination of zeta potential}

Zeta potential values range from -2.4 to -11.63 provide an indirect measurement of the net charge on the nanopar-

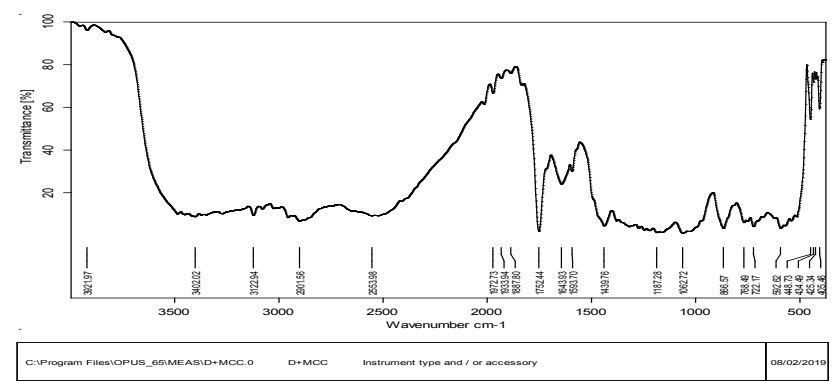

Fig. 4: FT-IR spectrum of drug and micro crystalline cellulose

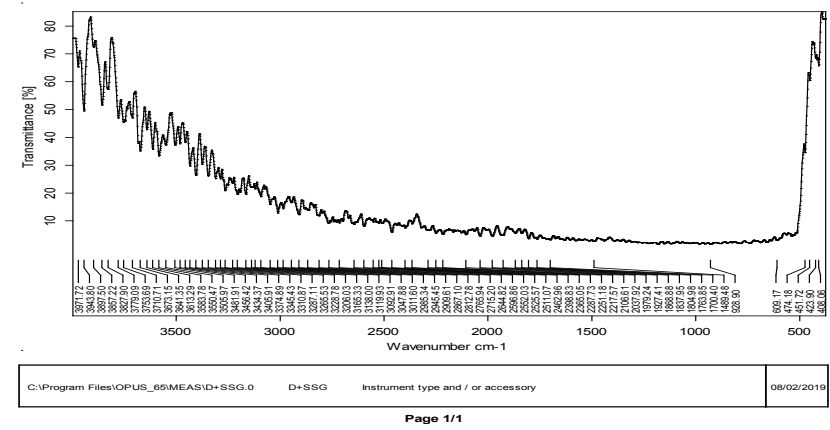

Fig. 5: FT-IR spectrum of drug and SSG

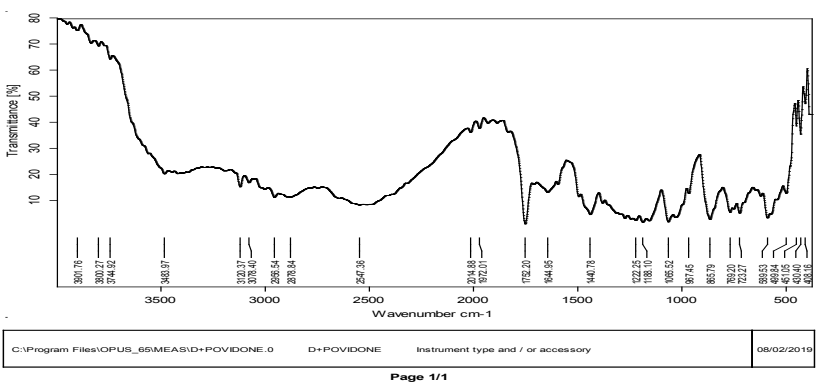

Fig 6: FT-IR of drug and CP

Table 4: Determination of particle size $(\mathrm{nm})$ and PDI

\begin{tabular}{llll}
\hline S. No. & Formulations & $\begin{array}{l}\text { Particle size } \\
(\mathrm{nm})\end{array}$ & $\begin{array}{l}\text { Polydispersity Index } \\
(\mathrm{Pl})\end{array}$ \\
\hline 1. & $\mathrm{F}_{1}$ & 843.4 & 0.673 \\
2. & $\mathrm{F}_{2}$ & 995.6 & 0.965 \\
3. & $\mathrm{F}_{3}$ & 539.8 & 0.324 \\
4. & $\mathrm{F}_{4}$ & 452.0 & 0.113 \\
5. & $\mathrm{F}_{5}$ & 367.4 & 0.452 \\
6. & $\mathrm{F}_{6}$ & 245.8 & 0.453 \\
7. & $\mathrm{F}_{7}$ & 325.4 & 0.325 \\
8. & $\mathrm{F}_{8}$ & 232.6 & 0.452 \\
9. & $\mathrm{F}_{9}$ & 528.5 & 0.124 \\
10 & $\mathrm{F}_{10}$ & 321.4 & 0.323 \\
\hline
\end{tabular}


ticle (NP) surface. Among all the formulations F2 is the best (-11.63) to characterize the superficial properties of NPs in a liquid state, zeta potential measurement is one of the most accessible. For this reason, the measurement of zeta potential can be routinely used as a pre-screening technique to control batch-to-batch consistency (Table 5).

\subsubsection{Determination of drug entrapment efficiency}

The DEE efficiency of Clopidogrel bisulphate nanoparticles from the formulas was found to be in the range of $30.10 \%$ to $94.4 \%$. By comparing with all the formulations, F2 determines the highest value in DEE. The increase in the viscosity of the drug and polymer solution also

Table 5: Determination of zeta potential for the nanoparticles

\begin{tabular}{lll}
\hline S. No. & Formulations & Zeta Potential $(-m v)$ \\
\hline 1. & $F_{1}$ & -4.5 \\
2. & $F_{2}$ & -11.63 \\
3. & $F_{3}$ & -8.54 \\
4. & $F_{4}$ & -5.5 \\
5. & $F_{5}$ & -12.4 \\
6. & $F_{6}$ & -8.6 \\
7. & $F_{7}$ & -2.4 \\
8. & $F_{8}$ & -3.7 \\
9. & $F_{9}$ & -6.4 \\
10. & $F_{10}$ & -8.6 \\
\hline
\end{tabular}

Table 6: Determination of drug entrapment efficiency for the nanoparticles

\begin{tabular}{lll}
\hline S. No. & Formulations & DEE\% \\
\hline 1 & $\mathrm{~F}_{1}$ & 75.15 \\
2 & $\mathrm{~F}_{2}$ & 94.4 \\
3 & $\mathrm{~F}_{3}$ & 30.10 \\
4 & $\mathrm{~F}_{4}$ & 32.52 \\
5 & $\mathrm{~F}_{5}$ & 54.67 \\
6 & $\mathrm{~F}_{6}$ & 42.43 \\
7 & $\mathrm{~F}_{7}$ & 46.72 \\
8 & $\mathrm{~F}_{8}$ & 67.42 \\
9 & $\mathrm{~F}_{9}$ & 82.61 \\
10 & $\mathrm{~F}_{10}$ & 88.45 \\
\hline
\end{tabular}

resulted in increased entrapment efficiency. Again, the entrapment efficiency of the Clopidogrel bisulphate nanoparticles of different polymers indicated that it is improved upon the increase in the molecular weight of the polymer as represented in Table 6 .

\subsubsection{Percentage cumulative drug release studies} for clopidogrel bisulphate nanoparticles

The dissolution studies were performed for the five formulations (F1-F5) of prepared clopidogrel bisulphate nanoparticles in comparison with the formulas. According to the Table 7 and Fig. $7 \& 8$, the results show that the formula F2 that contains PVP K-30 and L-arginine given the best release in 80 minutes in comparison with another formula, and the F2 formula determines the maximum drug release of $96.8 \%$.

The dissolution studies were performed for the remaining formulations F6-F10. Present study results show that the formulation F7 which contains tween-80

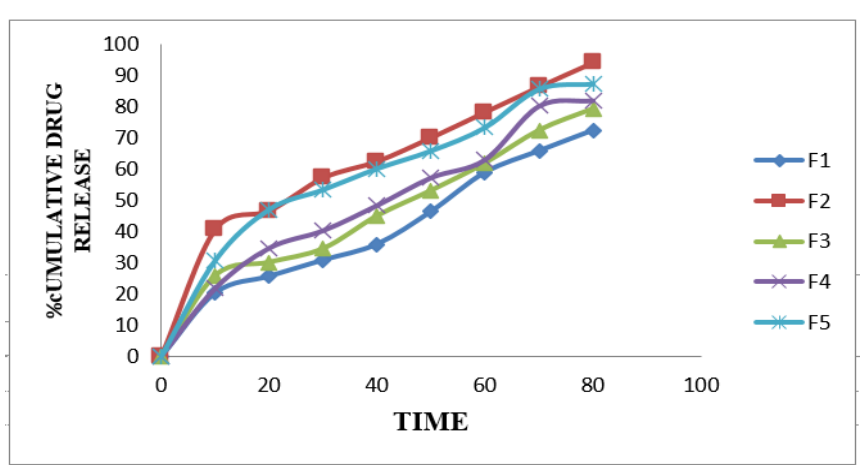

Fig. 7: Cumulative drug release of clopidogrel nanoparticles $\left(\mathrm{F}_{1}-\mathrm{F}_{5}\right)$

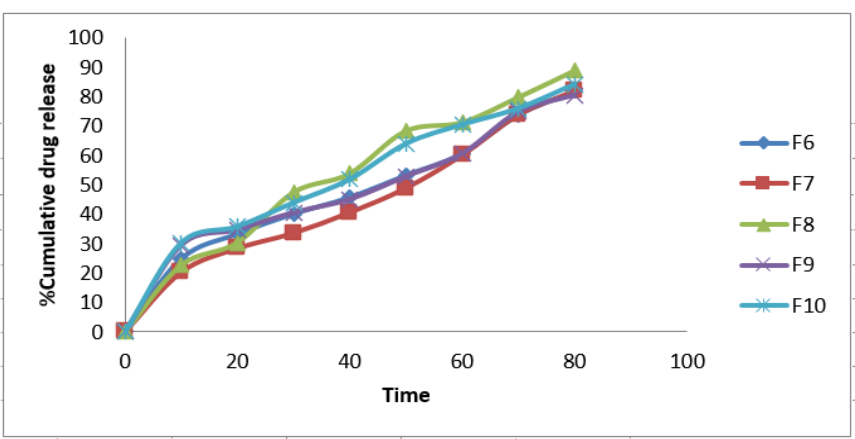

Fig. 8: Cumulative drug release of formulations $\left(F_{6}-F_{10}\right)$

opidogrel nanoparticles $\left(\mathrm{F}_{1}-\mathrm{F}_{5}\right)$

\begin{tabular}{lllllllllll}
\hline Time Interval (Mins) & $F 1$ & $F 2$ & $F 3$ & $F 4$ & $F 5$ & $F 6$ & $F 7$ & $F 8$ & $F 9$ & $F 10$ \\
\hline 0 & 0 & 0 & 0 & 0 & 0 & 0 & 0 & 0 & 0 & 0 \\
10 & 22.3 & 46.8 & 25.8 & 21.8 & 30.8 & 20.3 & 20.6 & 22.7 & 29.4 & 30.2 \\
20 & 30.8 & 52.7 & 34.3 & 34.9 & 36.1 & 24.7 & 25.3 & 30.2 & 33.5 & 37.4 \\
30 & 35.3 & 60.3 & 40.1 & 40.4 & 47.9 & 30.3 & 30.7 & 35.5 & 38.1 & 41.5 \\
40 & 46.8 & 65.1 & 45.0 & 48.1 & 53.8 & 35.8 & 39.6 & 47.7 & 43.8 & 49.6 \\
50 & 58.9 & 78.4 & 53.1 & 57.3 & 61.5 & 48.3 & 43. & 53.2 & 52.4 & 55.7 \\
60 & 65.8 & 86.9 & 61.9 & 63.1 & 73.7 & 60.1 & 56.2 & 68.8 & 60.7 & 63.5 \\
70 & 70.2 & 94.2 & 72.8 & 80.4 & 85.8 & 73.8 & 69.9 & 71.3 & 68.3 & 75.9 \\
80 & 78.1 & 96.8 & 79.3 & 83.7 & 87.3 & 81.5 & 84.8 & 79.8 & 80.6 & 82.1 \\
\hline
\end{tabular}


Table 8: Precompression parameters for superdisintegrants granules

\begin{tabular}{llllll}
\hline Formulation code & Bulk density $(\mathrm{g} / \mathrm{cc})$ & Tapped density $(\mathrm{g} / \mathrm{cc})$ & Angle of repose & Cars index (\%) & Hauser's ratio \\
\hline F1 & $0.53 \pm 0.02$ & $0.67 \pm 0.01$ & $21.25 \pm 1.56$ & $13 \pm 1$ & $1.1 \pm 0.03$ \\
F2 & $0.58 \pm 0.05$ & $0.68 \pm 0.01$ & $34.02 \pm 1.20$ & $13 \pm 1.51$ & $1.61 \pm 0.03$ \\
F3 & $0.49 \pm 0.09$ & $0.60 \pm 0.02$ & $37.01 \pm 1.70$ & $18 \pm 1.20$ & $1.30 \pm 0.03$ \\
F4 & $0.51 \pm 0.08$ & $0.64 \pm 0.01$ & $33.20 \pm 0.88$ & $18 \pm 2.51$ & $1.3 \pm 0.03$ \\
F5 & $0.55 \pm 0.04$ & $0.68 \pm 0.01$ & $29.4 \pm 1.48$ & $25 \pm 1.58$ & $1.3 \pm 0.03$ \\
F6 & $0.56 \pm 0.13$ & $0.62 \pm 0.02$ & $32.72 \pm 1.22$ & $12 \pm 1.55$ & $1.7 \pm 0.04$ \\
F7 & $0.58 \pm 0.24$ & $0.61 \pm 0.38$ & $24.87 \pm 1.32$ & $15 \pm 39$ & $1.2 \pm 0.04$ \\
\hline
\end{tabular}

Table 9: \% Cumulative drug release studies for clopidogrel bisulphate granules using superdisintegrants

\begin{tabular}{llllllll}
\hline Time interval & $F 1$ & $F 2$ & $F 3$ & $F 4$ & $F 5$ & $F 6$ & F7 \\
\hline 0 & 0 & 0 & 0 & 0 & 0 & 0 & 0 \\
10 & 23.5 & 22.5 & 23.8 & 24.9 & 34.6 & 20.5 & 21.8 \\
20 & 28.4 & 30.8 & 34.5 & 30.1 & 42.8 & 29.8 & 33.9 \\
30 & 35.9 & 39.5 & 38.8 & 38.5 & 51.6 & 38.9 & 40.8 \\
40 & 40.1 & 45.3 & 41.8 & 45.8 & 58.9 & 44.7 & 47.9 \\
50 & 49.8 & 57.8 & 52.6 & 51.9 & 64.6 & 58.9 & 58.5 \\
60 & 53.2 & 63.1 & 68.9 & 62.9 & 72.1 & 63.1 & 61.9 \\
70 & 68.7 & 70.8 & 71.8 & 69.8 & 86.6 & 69.8 & 67.5 \\
80 & 72.3 & 78.5 & 78.4 & 72.5 & 91.6 & 78.9 & 83.9 \\
\hline
\end{tabular}

has given the best release in 80 minutes in comparison with other formulations, whereas the F7 formulation has shown the maximum drug release of $84.8 \%$. Among the F2 and F7 formulations, F2 has shown the best release i.e., $96.8 \%$ in 80 mins.

\subsubsection{Precompression parameters for superdisintegrants granules}

All the formulations were evaluated for various micrometric properties. The Carr's Index value is from $12 \pm 1.55$ to $25 \pm 1.58$, bulk density ranges from $0.49 \pm 0.09$ to 0.58 \pm 0.05 , angle of repose ranges from $21.25 \pm 1.56$ to $37.01 \pm$ 1.70 , and Haussner's ratio ranges from $1.1 \pm 0.03$ to $1.7 \pm$ 0.04 . These values showed that the granules possess good flow properties (Table 8).

\subsubsection{Percentage cumulative drug release} studies for clopidogrel bisulphate granules using superdisintegrants

The dissolution studies were performed for the seven formulations of prepared clopidogrel bisulphate granules. According to the Table 9 and the results show that the formula F5 that contains the crospovidone gave the best release in 80 minutes in comparison with other formula and that formulation has shown the maximum drug release of $91.6 \%$ within 80 minutes (Table 9 \& Fig. 9).

\subsubsection{Comparison dissolution studies for drug loaded nano particles with tablets}

The comparative results of dissolution studies were performed for the $\mathrm{F}_{2}$ formulation of clopidogrel bisulphate nanoparticles and $\mathrm{F}_{5}$ formulation of clopidogrel
Table 10: Comparison studies for drug-loaded nanoparticles with tablets

\begin{tabular}{lll}
\hline $\begin{array}{l}\text { Time interval } \\
\text { (mins) }\end{array}$ & $\begin{array}{l}F_{2} \text { of } \\
\text { Nanoparticles }\end{array}$ & $\begin{array}{l}F_{5} \text { of Super } \\
\text { Disintegrants }\end{array}$ \\
\hline 0 & 0 & 0 \\
10 & 46.8 & 34.6 \\
20 & 57.2 & 42.8 \\
30 & 62.8 & 51.6 \\
40 & 78.4 & 58.9 \\
50 & 85.4 & 64.6 \\
60 & 89.8 & 72.1 \\
70 & 94.2 & 86.6 \\
80 & 96.8 & 91.1 \\
\hline
\end{tabular}

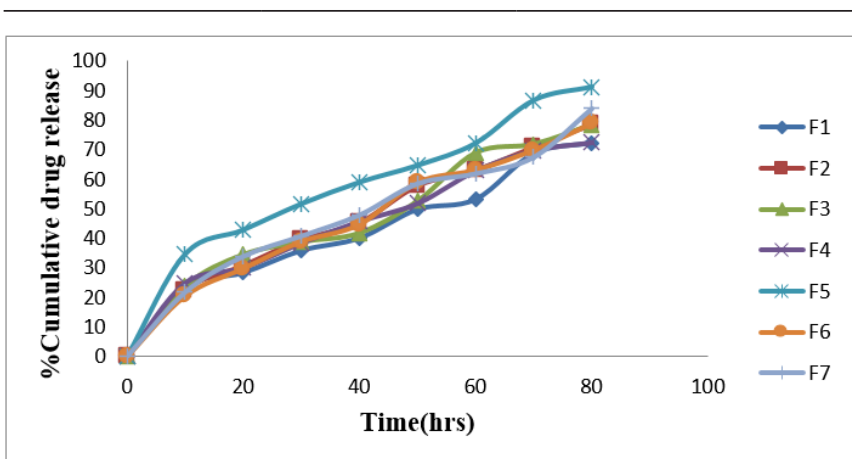

Fig. 9: \% cumulative drug release studies of clopidogrel tablets using superdisintegrants $\left(F_{1}-F_{7}\right)$

bisulphate granules using superdisintegrants (Table 10 \& Fig. 10). In comparison with the ideal formulations of nanoparticles and superdisintegrants technologies, the $\mathrm{F}_{2}$ of clopidogrel nanoparticles Shows the maximum drug release of $96.8 \%$, when compared with clopidogrel granules of $\mathrm{F}_{5}$ that is $91.1 \%$. By determining the method 


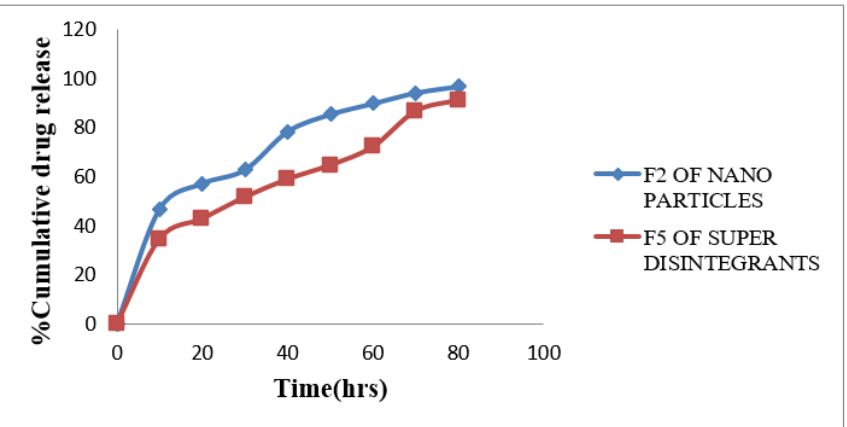

Fig. 10: Comparison dissolution studies for drug-loaded nanoparticles with granules

development technologies, we conclude that the dissolution nanoparticles have high solubility and bioavailability when compared with the superdisintegrants.

\section{CONCLUSION}

The present work involves method development technologies for improving the solubility and bioavailability studies by using the anti-solvent evaporation method and superdisintegrants technology. Preformulation studies of API characterization and drug excipient compatibilities were carried out by FT-IR spectroscopic methods. The results of $\mathrm{F}_{2}$ containing Clopidogrel bisulphate nanoparticles using surfactants as the optimized formulation showing the result of $96.8 \%$ of the drug in 80 minutes and formulation $\mathrm{F}_{5}$ of Clopidogrel bisulphate granules using superdisintegrants it releases $91.6 \%$ of the drug in 80 minutes by different polymers. The comparison studies showing the result of $\mathrm{F}_{2}$ formulation of Clopidogrel bisulphate nanoparticles having the higher cumulative drug release than the $\mathrm{F}_{5}$ formulation of Clopidogrel bisulphate granules using Superdisintegrants technology. This enables the active drug to convert into drug-loaded nanoparticles which enhances the solubility and bioavailability by improving method development technologies.

\section{ACKNOWLEDGEMENT}

We acknowlede the Principal of SVU College of Phar- maceutical Sciences, SV University, Tirupati, India for allowing us to fulfill our research work.

\section{REFERENCES}

1. Chougule D, Ghodke D, Shahar, Ghaste R. Fast Dissolving Tablets: An Overview. 2010.

2. Zhang L, Wang S, Zhang M, Sun J. Nanocarriers for oral drug delivery. J Drug Targ. 2013;2:515-527.

3. Salama NN, Eddington ND, Fasano A. Tight junction modulation and its relationship to drug delivery. Adv Drug Deliv Rev. 2006;58:15-28.

4. Lennemas H. Modeling gastrointestinal drug absorption requires more in vivo biopharmaceutical data: Experience from in vivo dissolution and permeability studies in humans. Curr Drug Metab. 2007;8:645-657.

5. Delmar K, Bianco-Peled H. Composite chitosan hydrogels for extended-release of hydrophobic drugs. Carbohydrate Polymers. 2016;136:570-580.

6. Gupta H, Bandari D, Sharma A. Recent trends in oral drug delivery: a review. Recent Patents on Drug Delivery and Formulation. 2009;3:162-173.

7. Jain N, Jain R, Thakur $\mathrm{N}$ et al. Nanotechnology: a safe and effective drug delivery system. Asian J Pharm Clin Res. 2010;3:159-165.

8. Michelson AD. Antiplatelet therapies for the treatment of cardiovascular disease. Nat Rev Drug Discovery. 9;2010:154-169.

9. Stratton MR. Exploring the genomes of cancer cells: progress and promise. Science. 2011;331:1553-1558.

10. Balasubramaniam J, Bindu K, Rao VU, Ray D, Haldar R, Brzeczko AW. Effect of superdisintegrants on the dissolution of cationic drugs. Dissolution Technologies. 2008;15: $18-25$.

How to cite this article: Paul AD, Neelima A, Prasanthi C, Kota N. Method Development Technologies for Clopidogrel Bisulphate by Improving Solubility and Bioavailability. Int. J. Appl. Pharm. Sci. Res. (2021);6(2): 15-21. doi: https://doi.org/10.21477/ijapsr.6.2.1

Source of Support: Nil.

Conflict of Support: None declared. 